panoply of simultaneous translation, undoubtedly dominated the scientific events.

Foreign participation, indeed, was the major feature of the symposium. Apart from the Minister's speech, there were four Bulgarian contributions (on geothermal and solar power, hydrogen fuel and secondary power sources). Otherwise, with the exception of one Polish contribution, all papers were contributed by Western experts, ranging from nuclear to hydraulic power sources, and from general policy to specific devices.

This willingness to borrow Western achievements is nothing new to Bulgaria. One exhibit at Plovdiv - that of the Progress organisation, established last year to help bridge the gap from research and development to large scale implementation- carried as its motto a quotation from Mstyslav Keldysh, late President of the Soviet Academy of Sciences, that it is not the nation which makes the first breakthrough who enjoys the benefits of a discovery but the one which implements it properly.

In 1976, said the Minister, when Bulgarian energy policy was revamped with the establishment of the National Energy Complex, Bulgaria had reached the position of one of the most developed nations in the world "in the energy sector at least", having increased specific consumption per head from $9 \%$ below world average in 1953 to twice the world average.

The new policy took a three-fold approach, stressing increased exploitation of local resources (mainly lignite), an expansion of nuclear generating capacity (which will reach $35 \%$ of the total generating capacity by 1990 , with subsequent introduction of nuclear district heating for Greater Sofia) and a major programme of energy-saving.

In spite of massive efforts at economy by industry and domestic consumers alike, these "passive measures" are not considered to be sufficient. Modernisation of existing plants, training of personnel to get the best use from their apparatus, and even the introduction of automated control systems for energy-intensive processes will all peak by the mid 1980 s leaving further gaps to be filled. These, stressed the Minister, can only be satisfied by new technologies.

Some of these will, of course, be of Bulgarian origin. Todoriev mentioned a new Bulgarian scheme, already in operation at the Maritsa-Istok-3 power station, which allows lignite to be burned without predrying - giving an overall fuel saving of some $5 \%$. Others, including solar energy, the use of the geothermal waters of the Rhodope mountains, and the pressing problem of secondary energy resources, may well, if one judges from the Plovdiv seminar, rely considerably - at least in the early stages, - on foreign know-how.

Vera Rich

\title{
Pugwash calls for new efforts to control chemical weapons
}

The Pugwash Workshop on Chemical Warfare has joined impatient voices calling for progress in negotiations on a chemical weapons (CW) disarmament treaty. At a meeting in Stockholm recently, the Workshop urged that the current situation in the negotiations be reappraised for the Biological Weapons Convention Review Conference, scheduled for 1980. The Review Conference is charged with assessing progress in CW disarmament as well. Most members of the Pugwash group also advocated the reopening of multilateral negotiations on a CW treaty, for there is a major weakness in the Biological Weapons Convention is that it allows research into new biological agents for 'defence'.

Since 1976, the US and the USSR have been having secret talks about chemical weapons disarmament - a subject earlier discussed at the multilateral Geneva Disarmament Conference. But the superpowers' bilateral talks have made no progress. They have instead taken the wind out of the Geneva negotiations, and many of the delegates to the Disarmament Conference have expressed themselves impatient with the stagnation. For example, the leader of the Swedish delegation, Mrs Inga Thorsson, tried recently to move things along when she suggested that the conference should begin its own CW negotiations in parallel with the superpowers. The Pugwash group urged the reopening of multilateral negotiations irrespective of the state of the bilateral talks.

A CW capability consists of different elements: laboratories for research and development, facilities where the weapons are made, and facilities where they are stockpiled. Any treaty aiming at $\mathrm{CW}$ disarmament must deal with all these different elements. The Workshop considered them in turn, asking for each whether it would be better to destroy it or convert it to civilian use, and how such measures could be verified.

Pugwash, a private affiliation of scientists interested in disarmament questions, is not an official government body, but it provides a useful arena for its members from east and west to test ideas and atmospheres. The temperature of the of ficial negotiations can be said to be above freezing simply because the Pugwash group is still functioning. At this meeting, the 30 participants produced nothing dramatic; but some of them (who preferred not to be named) were prepared to point to parts of its report with cautious optimism.

It was, for example, said to be a hopeful sign that the report contains a list - agreed by both sides - of six infrastructural recommendations for the verification of the destruction of declared stockpiles. Perhaps the most interesting of these points are that whatever international body is established to verify the destruction, it should have an independent technical capability, and that continuous presence of monitoring personnel at the destruction site would be necessary. The latter does not mean that the USSR, after years of refusing on-site inspection, has decided to allow them after all; but the report reflects agreement on more details of on-site inspection, and in this sense it may indicate a slight softening of the Soviet attitude.

What did emerge, however, from a visit the group made to the Swedish pharmaceuticals factory KabiVitrum AB, is that that on-site inspection need not jeopardise commercial secrets. In recent years, the Workshop has visited commercial chemical factories in West Germany and the United States, and a US Army chemical/munitions disposal facility.

Next year, the group plans to visit a site in East Germany. The visits have enabled the group to explore verification questions which could arise under a CW convention. Invasion of chemical factories by inspectors has long been opposed on grounds of commercial privacy; but as the Pugwash group visits more facilities in more countries, its experience suggests that opposition to some forms of international control of the chemical industry rests on shaky ground.

It was also reported that the discussion on confidence-building measures (CBM's) provoked more reaction than usual. CBM's are steps the sides can take to increase mutual trust: voluntary exchanges of technical and methodological information on chemical research and development related to $\mathrm{CW}$ problems, for example. The more trust there is between the sides, the fewer formal verification procedures are needed. Various CBM's have been discussed by previous meetings of the Workshop, but this one produced an additional concept for increasing mutual trust: 'obligatory CBM's under a CW convention'. The group felt that it could be useful to treat certain sorts of treaty provisions as CBM's: provisions, for example, which might be valuable but difficult to verify under a treaty. The discussion on CBM's was laced with controversy about which measures would be best to adopt; and at least one participant was surprised that both sides agreed to mention them favourably in the report.

Wendy Barnaby 